
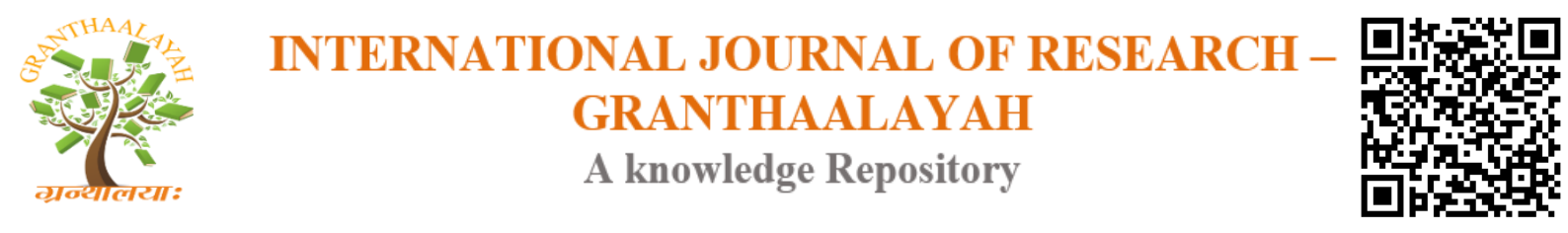

Social

\title{
MORAL JUDGMENT OF B.ED STUDENT TEACHERS IN RELATION TO THEIR SOCIAL MATURITY
}

\author{
Sharath Kumar C R ${ }^{* 1}$ \\ *1 Assistant Professor, B G S B.Ed College, Kuvempunagar, Mysore, Karnataka, India
}

\begin{abstract}
Education makes a man complete and socialized. The aim of education is to make a man physically, mentally, morally and totally mature, practical, job-oriented, independent, openminded, helpful and perfect in every field. It is through schools, that the aim of education can be achieved. In schools, the teacher plays an important role in molding the character of the child. Teachers are the building blocks of an educational edifice. They play a vital role in educating and teaching future generations. They are perceived as the architects of the second creation. Therefore training institutions have played a vital role in ensuring adequate development of knowledge, skills, and attitudes necessary for teaching. Education plays an elementary role in the society and we cannot even imagine a life without it. It is a determined element for the civilization of human society. It helps to develop healthy surroundings and it also generates advance community. The modern aim of the education is the wholesome balanced development of the personality. It means moral, social, spiritual, Intellectual, emotional and physical development. All these aspect are equally important for personality development. Personality does not exist in vacuum but to large extent depends upon social environment. Education develops the individual like a flower. This distributes its fragrance all over. Education provides mature person to the society. At the present age of competitive world every human being meets a lot of problem in his daily life. The root of most of human psychological problem is more in socially than psychologically. It is in social situation, a lack of moral judgment as well as Social maturity. Everyone needs knowledge about moral judgment and social maturity for leading a very healthy life in this world. The present study takes a position that moral judgment and social maturity is very important to the B.Ed student teachers and also for all students who live and grow in the complex social environment.
\end{abstract}

Keywords: Social Maturity; Moral Judgment and B.Ed Students.

Cite This Article: Sharath Kumar C R. (2017). "MORAL JUDGMENT OF B.ED STUDENT TEACHERS IN RELATION TO THEIR SOCIAL MATURITY." International Journal of Research - Granthaalayah, 5(9), 250-265. 10.29121/granthaalayah.v5.i9.2017.2240. 


\section{Introduction}

Education is regarded as the potential instrument of national development. Basically education deals with improvement of human resources. Nation transmits its heritage, recreation, culture, strengths through education. Its values it is the means of such immense importance that education has been enunciated $\mathrm{s}$ one of the fundamental human rights. Education is essential for revivalism of poverty. It is also important for solve economic planning and training in different service which are the internal components of the human resource development. Education is essential for everyone. It is the level of education that helps people earn respect and recognition and it is indispensable part of life both personally and socially. However, the unequal standard of education is still a major problem that needs to be solved.

Society is significant medium where certain quality of life and certain types of activity and occupation are provided with the aim of securing development based on the social needs. Since it is a stem of growth characteristics of teacher trainees should adapt to the society in which they live and to which they also expected to adjust and contribute the social maturity receives important at the present context.

Teacher Education refers to the policies and procedures designed to equip prospective teachers with the knowledge, attitudes, behaviors and skills they require to perform their tasks effectively in the classroom, school and wider community. A student teacher is a student in a College of Education who is undergoing training under the supervision of a qualified teacher educator in order to obtain a degree in Education. This term is also often used interchangeably with "PreService Teacher." It is a much broader term to include those students who are studying the required coursework in pedagogy as well as their specialty, but have not entered the supervised teaching portion of their training. In many institutions "Pre-Service Teacher" is the official and preferred title for all education students who are now-a-days called as student teachers.

According to Ingersoll (1999), the quality of a teacher is determined by his/her personality traits, teaching applications, and level of academic development. A teacher is empathetic, understands students emotions by their emotional maturity. Aware of personal and social responsibilities, upholds social values to keep up social maturity and Fair, and treats students equally and patiently is non-judgment through moral judgment. Warm, kind, friendly, sociable, familiar, trustworthy, earns students' trust, humble, dynamic, disciplinarian and confident. Encouraging, supportive, democratic, flexible, amicable, cooperative, and respectful of students; values their opinions, cheerful, compassionate, and enjoys helping others. the above characteristics, it is imperative that the student teacher should have Moral Judgment and Social Maturity. These two aspects are very important for a student teacher.

At the present age of competitive world every Human being meets a lot of problem in his daily life. The root of most of human psychological problem is more. Socially based than psychologically based. It is in social situation, a lack of moral judgment as well as Social maturity. So every human need knowledge about moral judgment and Social maturity for leading a very healthy life in this world. The present study takes a position that Moral Judgment and Social Maturity are very important to the B.Ed (Bachelor of Education) student teachers and also for all students who live and grow in the complex social environment. 


\subsection{Concept of Moral Judgment}

The word morality comes from the Latin word 'morals' which means custom relating to principles of right and wrong in behavior. According to Jean Piaget (1932) "All morality consists in a system of rules and the essence of all morality is to be sought in the respect which the individual acquires for these rules". However meaning of morality can be looked at from several standpoints such as that of the individual, the societal, the national and the international. While understanding morality there is always a possibility of confusing it with religion and even to equating it with religion. This is because traditionally morality has been a part of religion or even based on it in many parts of the world. But morality is different from religion except in countries where religion happens to be the basis of the social structure and political administration.

Rest, (1979) "Moral judgment is defined as the process by which a person decides what is morally right. That is, the structure a person relies on, to assign rights and responsibilities to oneself and others, is based on the way one interprets moral judgments

Jean Piaget (1965) proposed that moral judgment is the result of a process of sequential development in the child's reasoning abilities.

Bebeau, Rest and Narvaez, (1999) "Moral judgment is judging which action is morally right or wrong. Once a person is aware that various lines of action are possible, one must ask which line of action is more morally justified".

A human being gradually evolves from the extreme individualism of the infant and accompanying dependency on a few persons, chiefly the mother and father, the outgoing membership in a social group and dependency on its many members. So in the process of growing up, teachers are become more and more social, for which social maturity is needed.

\subsection{Social Maturity}

Social maturity is the ability to function in an appropriate responsible manner and understanding of the social rules and norms in place in a given culture and the ability to use that knowledge effectively. Self-care skill, healthy social interactions and an appreciation for others feelings are some indicators of social maturity in certain age groups. Increased research and interest in this field has resulted in new theories and strategies, with specific regard to practice that promotes development within the school system.

Social maturity means knowing what to do and striving for it by following role models to reach the desired level of acceptable social behavior. Social maturity is a long process. To be socially mature, students should be exposed to those people who are socially mature so that they can pattern their behavior accordingly. The students can try to reach the expectations of the social system, parents, teachers, siblings and peers who matter to them. Social maturity deals with learning to properly relate to acquaintances, friends and intimate relationships. It also involves understanding how to honor and respect those in authority; civil, parental, employer or spiritual. 
Hurlock (1950) "Social-development means attaining maturity in social-relations. It means the process of learning to confirm to group standards, morals, and traditions and becoming imbued with a sense of oneness, inter-communication and co-operation".

Raj, M. (1996), defines "Social maturity is a level of social skills and awareness that an individual has achieved relative to particular norms related to an age group. It is a measure of the development competence of an individual with regard to interpersonal relations, behavior appropriateness, social problem solving and judgment". Social maturity encompasses attainments in several domains, including independent functioning, effective interpersonal communication, interaction and responsibility i.e. contributing to the well-being of the society.

Social maturity is evidence by an individual's capacity for making and keeping friends. To be effective in his social relations, a person needs to acquire the social skills that enable him to deal with people tactfully and with understanding. He must be conscious of the interest of others, appreciative of their goals and supportive of their feelings of personal worth. Social maturity has to do with how well people understand the nature of the social world they live within. Social maturity is what enables us to function as healthy adults. Without it, we end up having a difficult time ourselves, or causing a lot of difficult times for other people. A high degree of social maturity has something to do with a high degree of social skill.

Aware of personal and social responsibilities, upholds social values to keep up social maturity. Fair, and treats students equally and patiently is non-judgmental through moral judgment. Warm, kind, friendly, sociable, familiar, trustworthy, earns students' trust, humble, dynamic, disciplinarian and confident. Encouraging, supportive, democratic, flexible, amicable, cooperative, and respectful of students; values their opinions, cheerful, compassionate, and enjoys helping others. The above characteristics, it is imperative that the student teacher should have moral judgment and social maturity. Moral Judgment and social maturity together may make people to make their decisions in right direction and in the creation of healthy society.

\subsection{Need and Significance of the Study}

The whole world is known as one global society despite of ethnicity, races, religion and other isolating factors. But race of advancement and competition, has given the global people, a kind in security also. A modern society cannot archive its aim of economic growth, technical development fully harnessing the talent of its citizen without quality education.

The quality of a nation depends upon the quality of its citizen. The quality of the citizens in term depends upon the quality of education and ultimately upon the quality of the teachers. The destiny of India is being shaped in its classroom, in which teachers play a very significant role as per the Kothari commission report on educational policy of nation. The teachers especially at the secondary level are the creator of the future citizens of the nation play significant role.

The teachers should be a collection of Nobel qualities like challenging and dynamic in the society. He/She not meant only for transference of knowledge equally concerned with inspiring the students towards achieving the characterised goals in the right way. In this background the 
institution of education play significant role in developing only intellectual ability or Moral Judgment but also Social maturity.

Moral Judgment is a development characteristics and it plays a significant role in decision making and influenced by cognitive and affective factors. All the three Moral development cognitive development and social learning and behavioral emphasize the relation between the moral development and Moral judgment. The development of moral judgment is influenced by some personal factors like age, sex, intelligence and family environment thus moral judgment is undisputed development changes with age and experience.

Society is significant medium where certain quality of life and certain types of activity are provided with the aim of securing child's development based on the social need. Since it is stem of growth characterizes of B. Ed student teachers should adopt to the society in which they also excepts to adjust and contribute the social maturity receives important at the present context. The B.Ed students social maturity through which can be respond right according to the Moral judgment. At the present age of competition world every human begin meets a lot of problem in his daily activities. The root of most human psychological problem is more socially based and psychological based. It is in Social situation.

This study take a position that Moral judgment and Social maturity are very important to the students who live and grow in the complex social environment hence there is a need to find out if any correlation between Moral judgment and Social maturity of B.Ed Student teachers.

Hence this investigation is a modest venture in this direction. It is in this context this investigation makes an attempt to study the correlation between Moral Judgment and Social

\section{Review of Related Literature}

The main aim of reviewing the related literature is to get an insight into the conceptual framework in the particular area, which enables the investigator in understanding the research approach, method, instrumentation and data analysis to be applied in the study.

\subsection{Studies Related to Moral Judgment}

Ghosh S (1957) has investigated social maturity of preschool Bengali children of Calcutta city belonging to different social economic groups. Thirty five nursery and kinder garden schools were randomly selected from the different regions of Calcutta and 40 per school children were selected from each school at random equally distributed in each area group. data were also collected by using standardized interview schedule on the mother of these selected children.

Wright and Cox (1967) conducted a research on "Relationship between Moral Judgment and Religious Belief". The sample consisted of 2276 pupils of whom $49.6 \%$ were boys and $50.4 \%$ girls from 6th forms of 96 maintained grammar schools in England. The major findings were as follows: 1. Nearly on all items, girls were more severe in their judgments than boys. 2. Age, subject studies and experience of co-education were not found to be related to moral judgment. 
3. Consistency, indices of religiosity were found to be severity of moral judgment. 4. The more ascetic the moral issue, the stronger the association with religious belief and practice.

Rao N (1978) conducted a research work on social maturity of high school students in Bangalore city. A sample of 1020 students was chosen from 50 secondary school in Bangalore. The selfconstructed questionnaires were used in this study.

VijayaKalra (1978) conducted a study entitled "A Study of Moral Judgment in Children belonging to different Mental and Socio-Economic Levels". The objective of the study was: To find out the level of development of moral judgment of children. Tools used in this study were Standard Progressive Matrices, Socio-Economic Status Scale (urban) and Moral Judgment Scale developed by the investigator. The sample comprised 1,000 girls selected from fifteen schools. Findings reported were: 1 . Intelligence was positively related with the level of moral judgment at all the three levels of socio-economic status. 2. The socio-economic status as positively related with the level of moral judgment at all the levels of intelligence.

Vora J I (1980) in his research work on social maturity of B.Ed student teachers in Gujarat. The sample size was 855 student teachers from Gujarat University, South Gujarat University, M S University. Some of the major findings were

- The male students were superior to the female students in their Social maturity.

- Age had no relation with Social maturity.

- The arts students were more social mature than science students.

- The higher Socio economic status had better social maturity

Zumari.P (1981) conducted a critical analysis on "Personality Needs Moral Judgment and Value Patterns of Secondary School Teachers'. The objective of the study was: To make a comparative study of the scores of male and female teachers in the inventory on values, personality needs and moral judgment. Tools used in this study were personality needs, values and moral judgment inventories. The findings reported were: 1. The male and female teachers expressed high preference for the theoretical values and needs and both have keen moral sense. 2. Urban male teachers were more moral than rural male teachers. 3. Male teachers secured better points in the aesthetic, political, social values than female teachers. 4. Male teachers below 30 years appeared to be more moral than those above 45 years and female teachers below 30 years also more moral than those above 45 years.

Colby, Anne et.al. (1983) undertook. "A Longitudinal Study of Moral Judgment". The objective of the study was: To verify Lawrence Kohlberg's theory of moral development through a new research design, the Standard Issue Scoring System, was reported. Kohlberg theorized that an individual progresses through several stages in attaining moral judgment. As children grow older, they are able to integrate diverse points of view on a moral conflict. Thus, each stage presupposes understanding gained at previous stages. The findings reported were: 1. Moral judgment was found to be positively correlated with age, socio-economic status. 2. There was a significant relationship between moral judgment and intelligence quotient and education. 
SavolukThongagamkhom (1983) has investigated the social maturity as a function of some psycho-socio-adjustment factors of B.Ed college students of north central region of Thailand. The scale was standardized on a sample of 922 students including boys and girls.

Puranik S D (1985) has studied the relationship of social maturity of pupils with organizational climate and teacher's morale in the primary school in Bangalore city. The sample consists of 70 schools 2634 students and 712 teachers. The study indicated the development if social maturity; autonomous climate, private management and unaided students and urban location of schools were most conductive factors.

Sarojamma Y H (1990) has conducted a comparative study of reaching ability and social maturity of over normal and under achievers of standard 8th. The final sample comprised of 476 boys and 524 girls. The social maturity scale by Sathyanarayana and swadha was used.

Bhushan A (1994) conducted a study on Social maturity across sex and family vocations. The sample comprised of 200 student teachers from 2 colleges equally divided between two sexes. Major variables used were sex value and family vocations. The tools used for data collection were the from $\mathrm{D}$ of value survey. The study highlights importance to social maturity, both male and female from service and non-service class had politeness as a subdivision on their maturity.

Bances Ann Leslie (1995) conducted a study on measuring the effect of participation in a peer facilitation project on sixth graders self-esteem. Social maturity and patterns of social choice. The population chosen for the study was rural mainstream sixth grade student. The sample was tested by socio metric pattern of choice. It was found that some significant difference; in social maturity for gender and there was significant relationship between self-esteem and social maturity.

Soloman (1995) designed a study to examine the "Relationship between Children's Moral Reasoning Maturity and their Legitimacy Judgment about Gender Stratification". The objectives of the study were: 1. To create a measure to assess children's interpretive and legitimacy judgments of gender stratification and 2. To assess the moral reasoning-legitimacy judgment relationship. The findings reported were: 1 . Boys is more advantaged in sport because they were highly skilled. Most children (66.1\%) judged gender stratification as illegitimate. 2. Older children, girls, and children with more sports experience were more likely to exhibit a difference between their interpretive and legitimacy judgments. 3. No significant relationship between children's moral reasoning maturity and their legitimacy judgment about gender stratification was observed.

\subsection{Studies Related to Social Maturity}

Piaget (1932) investigated "The Moral Judgment of the child" Piaget's main aim was to explore the nature of children's moral judgment and he questioned the children on their attitudes to rules, their judgment of right and wrong and their assessment of justices and fairness. He established that growth in moral judgment is gradual development process involving to the learning of rules by rewards, punishment or limitation but rather a process of cognitive. 
Wiggan (1941) the studies of Bright children have that they were superior in honesty and truthfulness as compared to children of average intelligence bright children occasionally also show weal moral characteristics. Intelligent conduct and it is to their personal advantage to act as the group expects them to act.

Whiting and Child (1953) studied the effect of pare natal punishment techniques on moral development. A central hypothesis of this study has been that love withdrawal of parents, in contrast to physical punishment techniques promotes various aspects of moral development. They divided the discipline technique into material or physical in the form of physical punishment and maternal deprivation and psychological discipline which is also known as "Love Withdrawn". The study showed that love orientated technique contributed to guilt by keeping the child oriented towards the goal of affection and at the same time arousing uncertainty as to the attainment of this goal.

Saraswathi T S, Sudarshan J and Saxena K (1977) conducted "A study on Moral Judgment of Indian children". 360 school children in the age group of 10 -15 years were assessed for level of Moral judgment using Sundareshan's adapted kohlberg's Moral judgment test. A significant relationship among the five issue scores yielded factors which accounted for $50 \%$ of total variance providing for the generality of moral judgment.

Tripathi and Mishra and others (1979) examined the development capacity for moral judgment in Indian children. The study conducted on 120 children of 3 age levels, two sex groups and two level of economic status. The result revealed main effect of age and interaction of three independent factors on the capacity for moral judgment was also found to be significant. The study concludes that although the capacity for moral judgment increases with age, the pattern is significantly by factor of sex and socio-economic status.

Paritha (1980) reported that family influence favorable for the American sample in the 15-16 years age group but not for the 12-13 years group which more or less indicated that reciprocity in parent child relationship is a favorable condition for the moral judgment of the children of upper middle class families in both culture. The result of the study is based on the data gathered on the rate of moral development in 120 urban middle class Indian Children (aged 12-16) and presents and their relationship of family environment factors to moral judgment development.

Bandyopadhyay (1981) made a research on growth and development of Moral Judgment on children. The objectives of his study was to adopt Piaget's stories, to study the growth of moral judgment with age and to examine the effect of Intelligence, socio-metric status, types of school and parental discipline on Moral judgment.

Bharagava (1986) studies on the development of moral judgment among the children at concrete and formal operational stages and its relationship with the variables of home and educational environment from the study it is revealed that the mean source on moral Judgment at the formal operational stage were significantly higher than those the concrete operational stages and measures of socio economic status were significantly correlated with moral judgment of concrete as well as formal operational levels. 
Urmil Rani (1991) studied the personal and educational environment factors as correlated of moral judgment secondary students. The study reveals that there is a significant positive relationship between intelligence and moral judgment.

Sridhar Y N (1995) studied "The extent of adult and group influence on Moral Judgment" The purpose of the study was to find out the relationship between Moral Judgment and certain personal and social variables such as sex, age, intelligence, family, life atmosphere and Sociometric status of high school students on Moral Judgment. The study resulted that young adolescents were more likely to follow the advice of parents as adult authorities and the gross pressure problems had not affected their moral decision making.

\section{Objectives of the Study}

The following are the objectives of the study

1) To assess the level of Moral judgment and Social Maturity of the B. Ed student teachers.

2) To study the Significant difference between Male and Female B. Ed student teachers with respect to their Moral Judgment.

3) To study the Significant difference between Arts and Science stream B. Ed student teachers with respect to their Moral Judgment.

4) To study the Significant difference between Government, Aided and Un-aided B. Ed college student teachers with respect to their Moral Judgment.

5) To study the Significant difference between Male and Female B. Ed student teachers with respect to their Social Maturity.

6) To study the Significant difference between Arts and Science stream B. Ed student teachers with respect to their Social Maturity.

7) To study the Significant difference between Government, Aided and Un-aided B. Ed college student teachers with respect to their Social Maturity.

8) Study the relationship between Moral Judgment and Social Maturity of B. Ed student teachers.

\section{Variables of the Study}

The following are the variable of the study

\section{Main variables:}

Moral Judgment

Social Maturity

\section{Background variables:}

Gender (Male / female)

Stream (Arts / Science)

Types of college (Government / Aided / Unaided)

\section{Methodology}

The researcher personally visited the B.Ed colleges and administered the Moral Judgment and Social Maturity scale to the selected sample of student teachers. The B.Ed student teachers were 
informed about the purpose of the study. They were instructed to fulfill in the tools and necessary clarification were given. Sufficient time was given to the B.Ed student teachers to fill the two tools.

\subsection{Sample of the Study}

Sample of the B. Ed Student Teachers belonging to Government, Private-Aided and Private UnAided B. Ed colleges of Mysore city. The sample was selected by using stratified random sampling technique.

The Study was conducted on a sample of 150 B. Ed student Teachers from different B.Ed colleges of Mysore city. The sample was selected using stratified random sampling technique giving representation to type of B.Ed colleges and streams.

The Sampling frame is as shown below

\begin{tabular}{|l|l|l|l|}
\hline \multirow{2}{*}{ Type of B Ed College } & \multicolumn{2}{c|}{ Stream } & \multirow{2}{*}{ Total } \\
\cline { 2 - 4 } & Arts & Science & \\
\hline Government B.Ed College Student Teachers & 25 & 25 & 50 \\
\hline Aided B.Ed College Student Teachers & 25 & 25 & 50 \\
\hline Unaided B.Ed College Student Teachers & 25 & 25 & 50 \\
\hline Total & 75 & 75 & 150 \\
\hline
\end{tabular}

\subsection{Research Tools Used}

The tool used to measure the variables and to collect the data are showed in the below table

Table showing tools used for collection of data with respect to the variables of the study.

\begin{tabular}{|l|l|l|l|}
\hline \multicolumn{1}{|c|}{$\begin{array}{c}\text { Variables } \\
\text { Measured }\end{array}$} & \multicolumn{1}{|c|}{ Tools Used } & \multicolumn{1}{c|}{ Developed By } & \multicolumn{1}{c|}{ Reliability } \\
\hline Moral Judgment & $\begin{array}{l}\text { Moral Judgment } \\
\text { Questionnaire }\end{array}$ & $\begin{array}{l}\text { Malathi and } \\
\text { Dr.M.Vanaja }\end{array}$ & $\begin{array}{l}\text { Split half Reliability } \\
(0.832 .)\end{array}$ \\
\hline Social Maturity & Social Maturity Scale & NaliniRao & $\begin{array}{l}\text { Split half Reliability } \\
(0.76)\end{array}$ \\
\hline
\end{tabular}

\section{Scoring Procedure of Moral Judgment Questionnaire:}

The Moral Judgment questionnaire with 15 items has situations followed by the three options a) Absolute b) Relative and c) Subjective. The items were marked as a, b, c and scored as 3, 2, and 1 respectively. The total maximum marks given to the questionnaire were 45 . The higher the score indicates the higher Moral Judgment level.

\section{Scoring Procedure of Social Maturity Scale:}

The final form of the questionnaire consists of 90 items. Each items was accorded a five point response speed, the intervals of which are labeled.

- Strongly Agree

- Agree 
- Neutral

- Disagree

- Strongly Disagree

Scoring key of the Questionnaire according to the nature of Items

\begin{tabular}{|l|l|l|l|l|l|}
\hline \multicolumn{1}{|c|}{ Nature of Item } & $\begin{array}{c}\text { Strongly } \\
\text { Agree }\end{array}$ & Agree & Neutral & Disagree & $\begin{array}{c}\text { Strongly } \\
\text { Disagree }\end{array}$ \\
\hline Positive & 5 & 4 & 3 & 2 & 1 \\
$17,21,24,26,36,39,41,42,50,51$, & & & & & \\
$52,54,56,57,59,63,74,77,89,90$ & & & & & \\
\hline $\begin{array}{l}\text { Negative } \\
1,2,3,4,5,6,7,8,9,10,11,12,13,\end{array}$ & & 2 & 3 & 4 & 5 \\
$14,15,16,18,19,20,22,23,25,27$, & & & & & \\
$28,29,30,31,32,33,34,35,37,38$, & & & & & \\
$40,43,44,45,46,47,48,49,53,55$, & & & & & \\
$58,60,61,62,63,64,65,66,67,68$, & & & & & \\
$69,70,71,72,73,75,76,78,79,80$, & & & & & \\
$81,82,83,84,85,86,87,88$ & & & & & \\
\hline
\end{tabular}

The successive response intervals were subsequently scored as 5, 4, 3, 2 and 1with the high score represents mature response. There was no right or wrong answers. The answer was checked against the key and point is given for each item ticked as per the key. The total point obtained gives a measure of Social Maturity. By this way the scoring is carried out for Social Maturity.

\subsection{Statistical Techniques used to Analysis the Data}

To analysis the data SPSS package was used and test the null hypothesis at 0.05 and 0.01 level of significance.

The following statistical techniques were used to analysis the collected data.

Descriptive Statistics: Mean, Standard Deviation and Percentile Analysis

Inferential Statistics:'t' test, One way ANOVA, and Pearson Product moment correlation.

\section{Findings of the Study}

It was found that:

1) A majority ( $60 \%$ ) of the B.Ed student teachers in Mysore city was found to possess average level of Moral Judgment and ( $16 \%$ ) were found to possess low level of Moral Judgment, Only ( $24 \%$ ) of the B.Ed students possess high level Moral Judgment.

2) A majority ( $45 \%$ ) of the B.Ed student teachers in Mysore city was found to possess average level of Social Maturity and ( $26 \%$ ) were found to possess low level of Social Maturity, Only ( $29 \%$ ) of the B.Ed students possess high level Social Maturity.

3) Significant difference was found in Moral Judgment of male and female B.Ed Student teachers comparing mean scores. It is found that the female student teachers have High Morality than their male counter parts. 
4) No significant difference between Arts and science B.Ed student teachers in their Moral Judgment.

5) Significant difference was found in Moral Judgment of Government, Aided and Un-aided B.Ed college student teachers comparing student mean scores. It is found that Aided college B.Ed student teachers having more Morality comparing than their Government and Un-aided college counter parts.

6) There is a significant difference in Social Maturity of male and female B.Ed Student teachers comparing mean scores. It is found that the female student teachers have High Social Maturity than their male counter parts.

7) No significant difference between Arts and science B.Ed student teachers in their Social Maturity.

8) Significant difference was found in Social Maturity of Government, Aided and Un-aided B.Ed college student teachers comparing student mean scores. It is found that Aided college B.Ed college student teachers having High Social Maturity comparing than their Government and Un-aided College counter parts.

\section{Educational Implifications}

The following are the educational implications of the study:

- The present study has shown that there is a need to develop specific curriculum for inculcation of values for different teachers training institutions. Certain specific theme training programmes were conducted to teacher's trainees. Hence the teachers can directly take up responsibility in providing moral education to their students.

- The ability of the society is determined by the persons those are having quality of intellectual and social values. The person who sties on to the value is regarded and acts as model to others. Value less people are odourless flower and rain the society.

- The present study has shown that there is a need to develop social maturity of B.Ed student teachers. Teachers are the nation builders. They affect the life of students a lot, so the teachers should be socially mature and they should be effective leader in dealing with the today's generation.

- The present study has shown that there is a significant difference in Moral Judgment of Male and female B.Ed student teachers. This appears to be a negative for the development of the society. Hence the B.Ed syllabus should include moral stories, illustration, and bibliographies of the great people. Important should be given social activities NSS and NCC. The colleges of education should organise the seminars, conference, symposia, workshop related to value education and value orientation programmes.

- The mean scores of science and arts stream student teachers is almost same with no significant difference suggestive that subject streams are not at all the reasons that effects the Moral Judgment of the individuals.

- The present scenario of society is characterized as being full of anger, hatred, distrust, disharmony, confrontation and above all degradation of human values. At this point of time, the colleges of education are considered more conducive place for the cultivation of certain desirable social skills among future teachers. They have to be trained to develop self-confidence, self-direction, social feeling, social and human values. Teachers and parents have to adopt the skills of social development to make their children socially 
concerned and aware along with inculcating in them social behavior. There is a dire need to bring stringent changes in the curriculum by introducing content and curricular activities that directly or indirectly enhances the social aspects of the individual.

- The teacher educators should adopt issue based teaching and learning strategies taking real life situation to make the individual aware of them self and others. It is essential to reform the curriculum with ample opportunities for partial knowledge. More ever it is the duty of the teacher educators who should be role models possessing high level of Moral judgment and Social Maturity to enhance these factors among the students who in turn can contribute to national development

- Co-curricular activities related to the affective domain should also be incorporated in the curriculum which should be a compulsory part of the curriculum. Educationists, educational administrators and teachers must acquaint their students about the pros and cons of moral education and with the help of a various mass media and modern means of communication the concepts of moral education should be published and popularized viz. newspaper, radio, TV, films, etc. It would be more beneficial and effective if special programmes are launched to develop moral values among students and this is possible only through inclusion of special courses on moral education in the schools.

- Value-oriented education in the light of moral education and moral awareness should be provided. Students should be allowed to listen to teacher's and adults' moral judgements. Students should lead discussions in groups in which they will have a chance to grapple actively with moral issues. Teachers should engage the classes in a good deal of passionate debate. He/she should try to leave much of the discussion to the students themselves, stepping in only to summarize, clarify, and sometimes present a view himself with encountering views which challenge their thinking and stimulate them to generate better arguments and formulate sound inferences.

- New approaches to develop value judgement among the students like value analysis, value discussion and jurisprudential inquiry through which the students can reach the solutions should be adopted. These approaches develop will-power, reasoning ability and rational judgement in the students.

\section{Suggestions for Further Study}

- The study was conducted to 150 Mysore District B.Ed Student teachers only. To make the study more comprehensive further studies can be conducted on a large sample.

- The present is confined only to the B.Ed student teachers. This study may be conducted D. Ed and M. Ed student teachers and also for in-service teachers.

- Many psychological factors like self-esteem, self-concept, intelligence, interest, emotions and cognitive development on may be examined for their effect on Moral Judgment and Social Maturity.

\section{Conclusion}

Moral Judgment and social maturity is an aspect that makes an individual adjust to the society at large. It is related to the development of the personality of student teachers. Moral Judgment and social maturity are essential for their daily life to adopt the class room situation. If a teacher having high Morality and socially mature they will guide their students properly. This study is 
aimed to know the Moral Judgment and Social maturity of B.Ed student teachers. In this chapter the hypotheses and major findings were given also further analysis has been recommended.

\section{References}

[1] Asthana, Anju. (1989). Social Maturity among School Going Children in the City of Lucknow.Fifth Survey of Educational Research (1988- 1992) Vol. II NCERT. pp. 865-866

[2] Bajpai, Amita. (1991), An Experimental Study of an Educational intervention Curriculum for Value-Development and its Facilitative Effect upon the Development of Moral Judgment. Fifth Survey of Research in Education (1988-92), New Delhi: NCERT, Vol- II, p.1333.

[3] Bandyopadhyay, R. (1981). Growth and Development of Moral Judgment in Children. Fourth Survey of Research in Education (1983-88), New Delhi: NCERT, Vol- I, p.336.

[4] Bhargava, I. (1986). Development of Moral Judgment among Children at Concrete and Formal Operational Stages and its relationship with the variable of Home and Educational Environment. Fourth Survey of Research in Education (1983-88), New Delhi : NCERT, Vol-I, p.344.

[5] Chaya A. Heblikar (2001). Moral Judgment of 10th Standard Student in Relation to their Parental Behavior, Child Rearing Practices, Emotional Maturity and Personality Traits.Unpublished Ph.D. Dissertation, Bangalore University, Bangalore.

[6] Colby, Anne. et.al. (1983).A Longitudinal Study of Moral Judgment. Data retrieved on 18th may, 2015 from http://www.uni-konstanz.de/ ag-moral/pdf/Lind-1989_kohlberg-measurement- review. PDF.

[7] Geethanath, P.S. (1988).Moral Judgment in Relation to Some Selected Variables. Fifth Survey of Research in Education (1988-92), New Delhi : NCERT, Vol- II, p.1336.

[8] Gupta, K.M. (1991). The Structure of Teacher Educators in Moral Judgment. Fifth Survey of Research in Education (1988-92), New Delhi: NCERT, Vol- II, pp.1338.

[9] Harold H. Titus, (1943). Introduction about Morality in the book Ethics and Morality. Data retrieved on 18th March,2015 from http://en.wikipedia.org/wiki/Morality\#Morality_and_ethics

[10] Harold H. Titus, (1943). Theories of Moral Judgment. Data retrieved on 3rd April, 2015 from http://www.philosophy-religion.org/handouts/ pdfs/ch7-ethics.pdf

[11] Jennifer Nado, Daniel Kelly, Stephen Stich, (2006). Haidts Model, Greene's Model, Hauser Model of Moral Judgment. Data retrieved on 15th May, 2015 from http://www.rci.rutgers. edu/ stich/Publications/Papers/Moral\% 20 Judgment $\% 20 \quad \% 20 \quad$ FINAL\%20DRAFT\%20\%20web.pdf - 277

[12] Jennifer Nado, Daniel Kelly, Stephen Stich, (2006). Meaning of Moral Judgment. Data retrieved on 21st April, 2015 from www.texttribe.com/routledge/M/Moral\%20judgment.html

[13] Y.S., Park, J.W., Son, Y.J., Han, S.S. (2004). Longitudinal Study on the Development of Moral Judgment in Korean Nursing Students. Data retrieved on 20th May, 2015 from http://www.ncbi.nlm. nih.gov/pubmed/15176639.

[14] Kohlberg Lawrence, (1984). Levels of Moral Judgment. Data retrieved on 10th March, 2015 from http://www.crvp.org/book/Series05/V-4/note_to_chapter_xiii.htm

[15] Kumari, P. (1981). Personality Needs Moral Judgment and Value Patterns of Secondary School Teachers. Fourth Survey of Research in Education (1983-88), New Delhi: NCERT, Vol- I, p.413

[16] Manga Devi, (1987). Influence of Pre-School Education on Social Maturity, Language Skills and Scholastic Achievement of Students with and without Anganwadi Background at Primary Level. Data retrieved on 20th may 2015 from http://dspace.vidyanidhi.org.in:8080/ space/handle/2009/3870

[17] Mangal, S.K. (2007).Advanced Educational Psychology. New Delhi: Prentice Hall of India Pvt. Ltd.

[18] Meena Sharma, K.M. and PrabhatShukla, (1999).Moral Judgment in relation to Socio-Economic Status and School Background. The Educational Review, 1999 Jan, Vol-CV-No 1, pp. 9-13. 
[19] PattramonJumpangern, (1986). Social Maturity of Teachers-College Students of Western Region of Thailand, in the Context of some Psycho-Socio Factors. Fourth Survey of Educational Research (1983-1988) Vol. I. p.248 - 280

[20] Peter Unger, (1996). Data retrieved on 25th May, 2015 from http://www.rci.rutgers.edu/ stich/Publications/Papers/Moral\%20Judgment\%20-\%20FINAL\%20

DRAFT \%20-\%20web.pdf

[21] Piaget, (1932).Definition of Morality. Data retrieved on 20th March, 2015 from http://dspace.vidyanidhi.org.in:8080/dspace/handle/ 2009/3594.

[22] Piaget, J. (1965). Definition of Moral Judgment "The Moral Judgment of the Child". New York: Free Press. (Original work published 1932.)

[23] Prabhawati, Kumari. (1987). Personality Needs Moral Judgment and Value Patterns of Secondary School Teachers. Fourth Survey of Research in Education (1983-88), New Delhi: NCERT, VolI, p.413.

[24] Pradhan, G.C. (1992). Variation in the Development of Moral Judgment of School Students in Different Types of Schools in Relation to General Intelligence, Personal Values, Socio-Economic Status and Sex. Fifth Survey of Research in Education (1988-92), New Delhi: NCERT, Vol- II, p.1343.

[25] PraedaoKlengklao, (2007). Parenting Styles and Moral Judgment in Juvenile Delinquency in Southern Thailand. Data retrieved on 15th -april, 2015 from http://www.li.mahidol.ac.th/thesis/2550/ cd410/ 4636914.pdf

[26] Prahallada, N.N. (1982). An Investigation of the Moral Judgment of Junior College Students and their Relationship with Socio-Economic Status, Intelligence and Personality Adjustment. Fourth Survey of Research in Education (1983-88), New Delhi: NCERT, Vol- I, p.414.

[27] Puranik S.D. (1985). Relationship of Social Maturity of Pupils with Organizational Climate and Teacher's Morale in the Primary Schools of Bangalore City. Data retrieved on 10th april, 2015 from http://dspace. vidyanidhi.org. in :80 80 / dspace/handle/2009/2653

[28] Raj, M. (1996). Definition of Social Maturity, Encyclopedia Dictionary of Psychology and Education. New Delhi.

[29] Anmol publications. Ramesh Kumar Mohanty, (2008). Development of Moral Judgment in Elementary School Children in Relation to their Home Environment, Socio-Economic Status and Intelligence.Abstracts of Research Studies by Teacher Education Institutions in India, Vol. III, CASE, The M.S. University of Baroda, Vadodara, p.237.

[30] Robert Kegans, (2008). Development of Social Maturity. Data retrieved on 10th March, 2015 from http://the-mouse-trap.blogspot.com/ 2008/09/ robert-kegans-stages-of-social maturity.html

[31] SaovalukThongngamkhom, (1983). Social Maturity as a Function of Some Psycho-Socio Adjustment Factors of B.ED College Students of North-Central Region of Thailand.Fourth Survey of Educational Research (1983-1988) Vol. I. p. 261.

[32] Saraswathi.T.S. (1978).Perceived Maternal Disciplinary Practices and their relation to Development of Moral Judgment. Fourth Survey of Research in Education (1983-88), New Delhi: NCERT, Vol- I, p.426.

[33] Sarojamma, Y.H. (1990). Reading Ability and Social Maturity of Over, Normal and Underachievers of Standard VII.Fifth survey of Educational Research (1988-1992) Vol. II, NCERT. pp. 1912-1913

[34] Singh, R.S.(1983). Children's Moral Judgment in relation to Prolonged Deprivation and Parental Attitudes. Fourth Survey of Research in Education (1983-88), New Delhi: NCERT, Vol- I, p.439.

[35] Soni, J.C., (1984). Moral Judgment in School Going Children of Rural Area of Delhi belonging to different Castes and Sexes. Fourth Survey - 284 - of Research in Education (1983-88), New Delhi: NCERT, Vol- I, p.208.

[36] SrinivasRao, (1984). Moral Judgment in Children. Fourth Survey of Research in Education (1983-88), New Delhi: NCERT, Vol- I, p.208. 
[37] Stephens, Deidra Graves, (2009). Parental Attachment and Moral Judgment Competence of Millennial Generation College Students. Data retrieved on 15th April, 2010 from http://digitalcommons.unl.edu/dissertations/ AAI3350011/-

[38] Surjit Singh, Dr. Praveen Thukral, (2010). Social Maturity and Academic Achievement of High School Students. Data retrieved on 23th May 2015 from http://www.ampublisher.com/July\%202010/ SIR-1007-012.pdf

[39] TorsenHusen, T. Neville Postleth Waite, (Editors-in-chief), (1999). The International Encyclopedia of Education, Volume 6. New York:' Pergamon Press. p.3413. Trivers, R.L. (1971). The Evolution of Reciprocal Altruism. Q. Rev. Biol. 46,

[40] VijayaKalra, (1978). Moral Judgment in Children belonging to different Mental and SocioEconomic Levels. Third Survey of Research in Education, New Delhi: NCERT, Vol- III, p.144.

*Corresponding author.

E-mail address: sharu.krn@gmail.com 